ISSN: 1907-9931 (print), 2476-9991 (online)

\title{
Computational model tahanan kapal untuk menentukan kebutuhan daya kapal bulk carrier 8664 DWT
}

\author{
Computational model of ship resistance for estimate engine power of bulk carrier ship 8664 \\ DWT
}

\author{
Erik Sugianto*, Arif Winarno
}

Universitas Hang Tuah Surabaya

*Corresponding author email: erik.sugianto@hangtuah.ac.id

Submitted: 06 Desember 2017 / Revised: 22 Desember 2017 / Accepted: 22 Desember 2017

http://dx.doi.org/10.21107/jk.v10i2.3411

\begin{abstract}
ABSTRAK
Faktor utama dalam menentukan daya mesin kapal adalah tahanan kapal. Umumnya, tahanan kapal dihitung menggunakan percobaan model pada towing tank. Namun biaya yang diperlukan sangat besar. Penelitian ini bertujuan menentukan tahanan total kapal dan memperkiraan kebutuhan daya mesin kapal bulk carrier 8664 DWT. Kapal dimodelkan menggunakan software perkapalan, kemudian perhitungan tahanan kapal dan kebutuhan daya kapal dilakukan. Selain itu dilakukan validasi hasil dengan perhitungan matematis Holtrop dan analisa perbandingan hasil dengan penelitian sebelumnya. Hasil analisa untuk kecepatan dinas maksimal 14 knots menunjukan tahanan total kapal adalah 286. $75 \mathrm{kN}$ dan kebutuhan dayanya adalah $2950.31 \mathrm{~kW}$. Sedangkan dengan perhitungan matematis Holtrop dihasilkan tahanan total $256.59 \mathrm{kN}$, ini terdapat selisih 10.52\% dengan hasil permodelan komputer.
\end{abstract}

Kata kunci: tahanan, model, daya, kapal

\begin{abstract}
The main factor in determining the ship's engine power is the ship's resistance. Generally, ship resistance is calculated using model experiments on towing tanks. But the cost is high, this research aims to determine the total ship resistance and estimate the power requirement of bulk carrier 8664 DWT. The bulk carrier is modeled using shipbuilding software, then the calculation of the ship resistance and the ship's power requirement. In addition to the validation of results with mathematical calculations Holtrop and comparative analysis of results with prior research. The analysis result for a maximum speed of 14 knots shows the total ship resistance is $286.75 \mathrm{kN}$ and its power requirement is $2950.31 \mathrm{~kW}$. While with mathematical calculations Holtrop generated a total resistance of 256.59 $\mathrm{kN}$, there is a difference of $10.52 \%$ with the results of computer modeling.
\end{abstract}

Keywords: resistance, model, power, ship

\section{PENDAHULUAN}

Biaya operasional kapal (BOP) merupakan biaya yang dikeluarkan untuk mengoperasikan kapal dalam sebuah pelayaran. Terdapat biaya langsung yang terdiri dari biaya tetap dan tidak tepat serta biaya langsung. Dari semua komponen BOP, biaya bahan bakar minyak (BBM) menjadi biaya terbesar atau sekitar 33\% dari total BOP (1).
Besar kecilnya konsumsi BBM kapal dipengaruhi oleh spesifikasi mesin utama, daya kapal, jarak pelayaran dan kecepatan kapal ketika beroperasi (2). Sehingga penentuan mesin utama dan daya kapal yang tepat akan menjadi penting dalam konsumsi BBM.

Spesifikasi mesin kapal dan besarnya daya diperoleh dari perhitungan tahanan kapal dan berbagai faktor pada sistem propulsi kapal. Saat ini, tahanan kapal dapat hitung dengan 
menggunakan metode percobaan pada towing tank, namun biaya yang diperlukan untuk melakukan pengujian sangat mahal. Metode numerik dengan menggunakan software perkapalan dapat menjadi salah satu solusi dalam menghitung tahanan kapal terutama kapal yang mempunyai koefisien block besar dan kecepatan rendah seperti kapal pengangkut curah kering atau bulk carrier.

\section{MATERI DAN METODE}

\section{Lokasi dan Waktu Penelitian}

Peneltian dilakukan di Laboratorium Fluida Fakultas Teknik dan IImu Kelauatan
Universitas Hang Tuah S]urabaya. Penelitian dilakukan antara bulan Februari sampai Agustus 2017.

\section{Kapal Bulk Carrier 8664 DWT}

Pada penelitian ini, kapal yang digunakan model adalah Kapal Bulk Carrier 8664. Kapal Bulk Carriar adalah kapal niaga yang dipergunakan untuk mengangkut muatan curah kering seperti beras, gandum, jagung, nikel, batu bara dan bijih-bijihan lainnya. Kapal bulk carrier 8664 DWT mempunya ukuran dan data utama sebagai berikut:

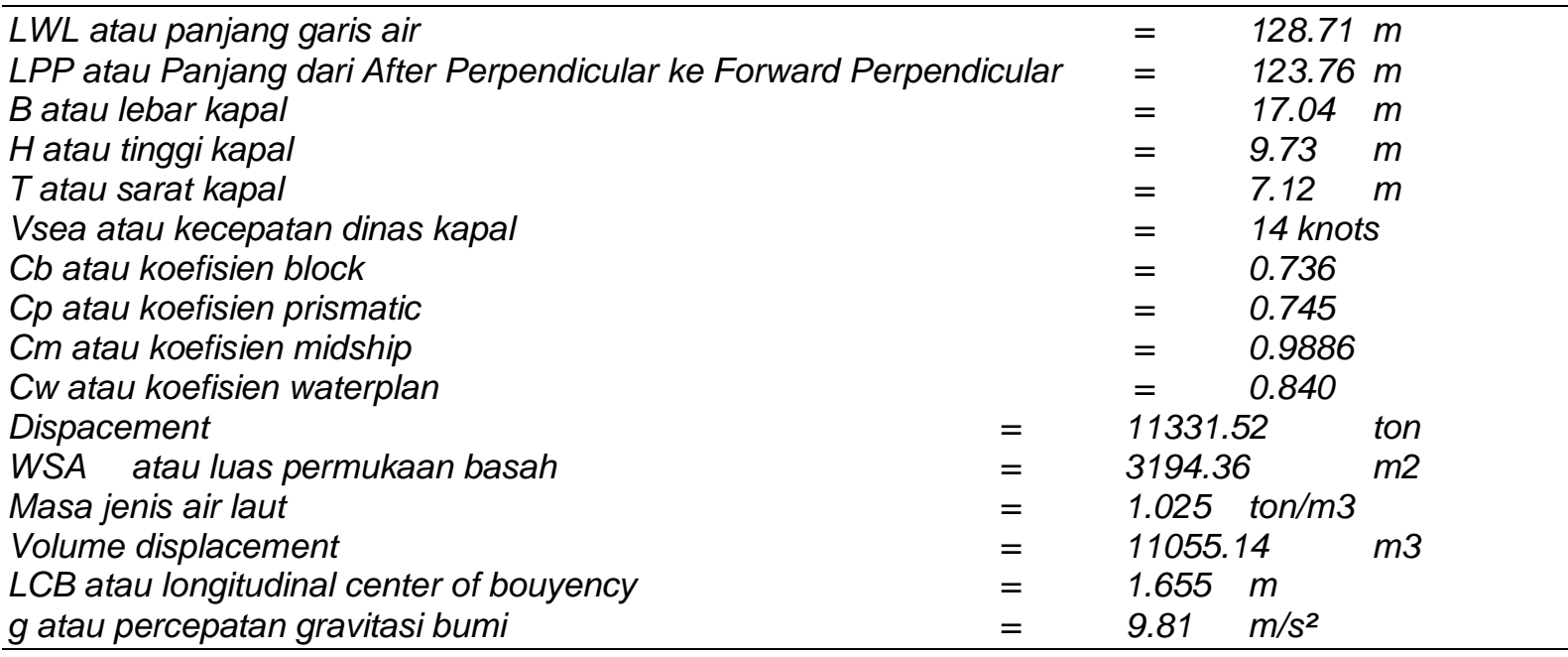

\section{Software Perkapalan}

Permodelan yang dilakukan pada software perkapalan adalah bentuk badan kapal yang tercelup dalam fluida atau air laut. Software perkapalan yang digunakan adalah Software Maxsurf versi academic.

\section{Metode Tahanan Kapal Matematis Holtrop}

Tahanan kapal pada suatu kecepatan adalah gaya fluida yang bekerja sehingga melawan gerakan kapal tersebut (4). Tahanan total kapal dapat dibagi menjadi tiga yakni tahanan viskositas $(\mathrm{Rv})$, tahanan gelombang (Rw) dan tahanan udara $(\mathrm{Ra})$. Karena nilai tahanan udara sangat kecil yakni sekitar $4 \%$ dari tahanan total, maka perannya sering diabaikan (5). Formula tahanan total kapal (RT) dapat ditulis seperti persamaan 1.

\section{HASIL DAN PEMBAHASAN}

\section{Permodelan}

Perbedaan utama bulk carrier dengan kapal lain adalah pada bagaimana cara memuat
$\mathrm{RT} \quad=\mathrm{Rv}+\mathrm{Rw}+\mathrm{Ra}[\mathrm{N}] \quad$ Persamaan 1

Komponen tahanan gesek dapat ditunjukan seperti persamaan 2. Cf merupakan koefisien tahanan gesek kapal dan $\mathrm{K}$ merupakan konstanta. Tahanan gesek merupakan komponen tahanan yang terkait dengan gaya akibat gesekan antara molekul fluida (5). Tahanan ini dipengaruhi oleh kecepatan kapal, viskositas fluida dimana kapal berada dan luas permukaan kapal yang tercelup air. Secara umum formula tahanan gesek kapal dapat ditulis seperti persamaan 6 (6).

$R f=1 / 2$ Cf $(1+k)^{*} \rho^{*} \mathrm{Cf}^{*} \mathrm{~S}^{*} \mathrm{~V}^{2}[\mathrm{~N}]$ Persamaan 2 Dimana Rf merupakan tahanan gesek, $\rho$ merupakan massa jenis fluida $(\mathrm{kg} / \mathrm{m} 3)$, Cf merupakan koefisien gesek, $\mathrm{S}$ merupakan permukaan basah $\left(\mathrm{m}^{2}\right)$, dan $\mathrm{V}$ adalah kecepatan kapal $(\mathrm{m} / \mathrm{s})$.

barang yakni barang secara langsung dicurahkan ke dalam tangka muatan. Selain itu, kapal ini juga memiliki keistimewaan pada konstruksinya yakni terdapat top side tank dan hopper side tank yakni tangki berbentuk 
segitiga pada keempat sisi pojok pada setiap ruang muatannya. Data kapal bulk carrier

8664 DWT yang dimasukan dalam software perkapalan seperti pada gambar 1 .

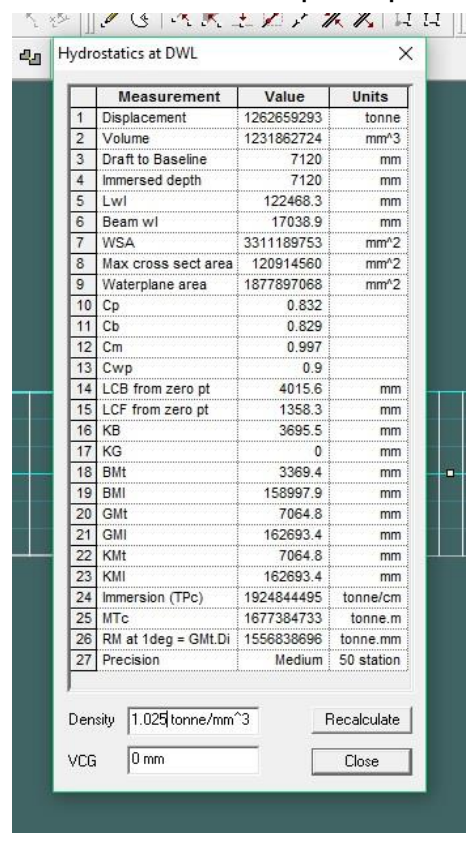

Gambar 1. Data Kapal pada software perkapalan

Permodelan kapal bulk carrier 8664 DWT dilakukan pada software perkapalan. Model ini merupakan ganti dari model nyata kapal atau model kapal dengan skala tertentu. Pada software ini terdapat gambar dasar bentuk bulk carrier yakni model lambung kapal yang berada dalam fluida. Data ukuran utama kapal kita gunakan untuk membuat model seperti yang kita inginkan sampai semua komponen ukuran utama dan koefisien kapal memenuhi bentuk kapal bulk carrier. Gambar hasil model seperti gambar 2.

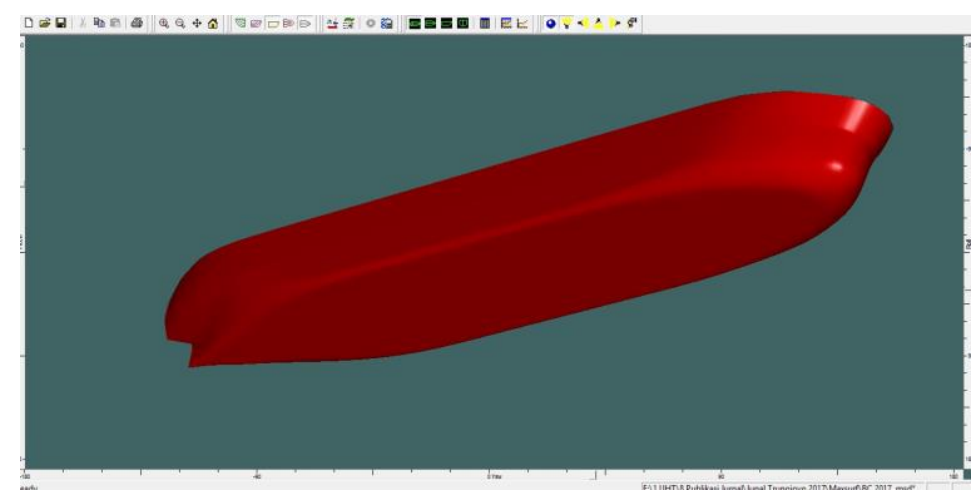

Gambar 2. Model lambung kapal yang tercelup air

\section{Kecepatan, Hambatan dan Daya}

Perhitungan tahanan dilakukan dengan motode Holtrop dengan bebagai variasi kecepatan kapal dari 0 knots sampai 20 knots. Motode holtrop merupakan metode perhitungan tahanan dengan menggunakan formula pendakatan matematis. Hasil perhitungan didapatkan grafik seperti gambar 3.

Dari gambar 4 diketahui pada kecepatan 0 sampai 2.5 knots tahanan kapal adalah $0 \mathrm{kN}$.
Hal ini terjadi karena kapal dianggap sedang ditarik dengan kapal tongkang, sehingga kapal bergerak namun sistem propulsi kapal sedang diam. Selanjutnya pada kecepatan 3 knot sampai 20 knots, tahanan berangsur-angsur naik mengikuti kenaikan kecepatan kapal. Tren garis antara kecepatan dan tahanan juga sesuai dengan persamaan Lewis pada persamaan 6 yakni hambatan adalah kuadrat kecepatan kapal. Untuk kecepatan maksimum kapal bulk carrier dengan 14 knots maka nilai tahanannya adalah $286.75 \mathrm{Kn}$. 


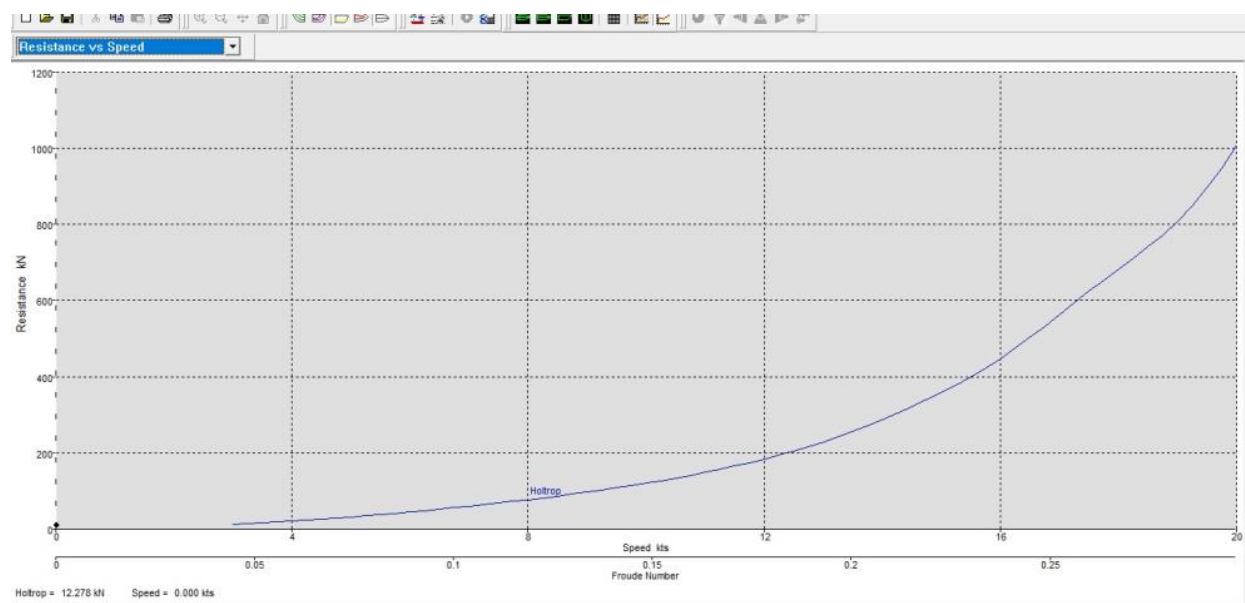

Gambar 3. Grafik kecepatan vs hambatan

Daya kapal yang didapatkan dari perhitungan software perkapalan ini dalah daya efektif kapal karena pengaruh poros, bentuk lambung dan daerah pelayaran belum dimasukan. Hasil perhitungan daya dapat dilihat pada gambar 4. Linier dengan nilai tahanan kapal, pada kecepatan 0 sampai 2.5 knots, daya kapal bernilai 0 . Ini sesuai dengan persamaan 3 yakni daya efektif merupakan perkalian antara tahanan dengan kecepatan.

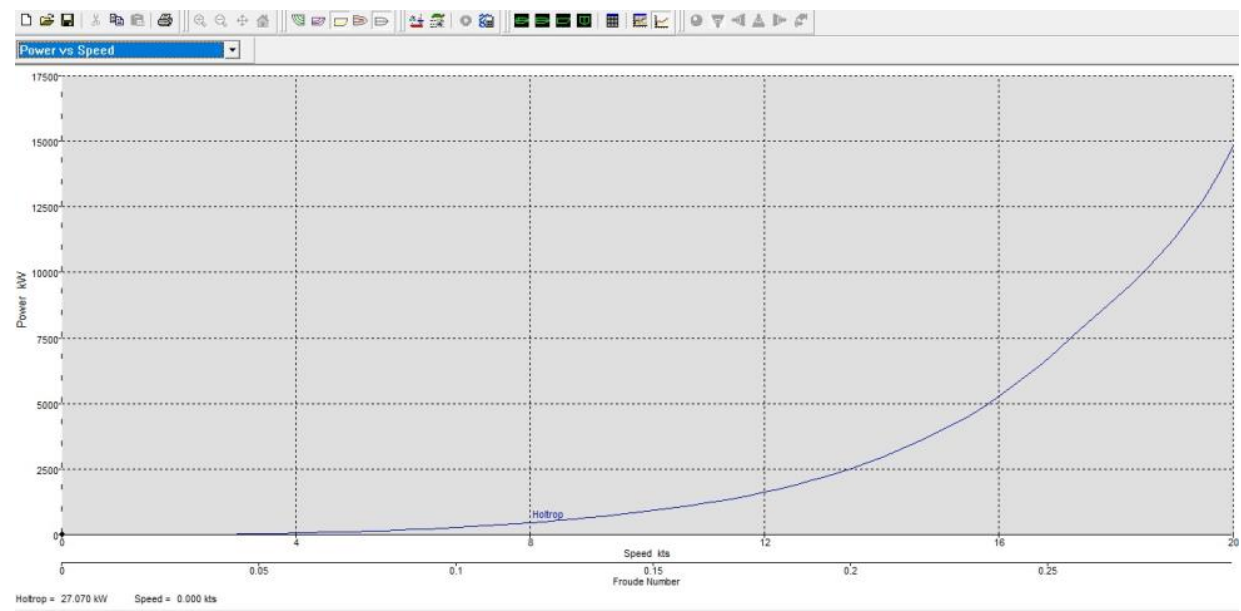

Gambar 4. Grafik kecepatan vs Daya

Tren garis kecepatan dan daya hampir sama dengan kecepatan dan tahanan kapal yakni semakin tinggi kecepatan maka daya yang diperlukan semakin tinggi. Persamaan garis antara kecepatan dan daya juga merupakan fungsi kuadrat linier. Untuk kecepatan kapal bulk carrier 14 knots didapatkan daya efektif kapal $2950.31 \mathrm{Kw}$. Tampilan alur gelombang ketika kapal bergerak dapat dilihat pada gambar 5. Gambar tersebut merupakan gambar tampak atas ketika kapal sedang berlayar dengan kecepatan tertentu.

\section{Validasi Perhitungan Tahanan Holtrop}

Setelah mendapatkan nilai dari notasi seluruhnya yang meliputi masa jenis fluida adalah $1.025 \mathrm{Kg} / \mathrm{m} 3$, kecepatan dinas kapal adalah $7.2 \mathrm{~m} / \mathrm{s}$, luas permukaan basah adalah
$3301.14 \mathrm{~m} 2$, koefisien tahanan gesek adalah $0.00153^{*} 1.44$, koefisien tahanan udara adalah 0.000434 dan wake making resistense adalah $0.000434 * 111162.19$ maka didapat kan besarnya tahanan totalnya (RT), yakni:

$R_{T}=1 / 2{ }^{*} 1,025 * 7.2^{2 *} 3301.14 *[$

$(0.00153 * 1.24+0.000466]+$

$(0.000434 * 111162.19)=256.588 \mathrm{kN}$

Perbandingan tahanan total antara penggunaan software komputer dan metode matematis holtrop dapat dilihat pada gambar 6 . Pada grafik tersebut kecepatan dinas kapal 14 knots menjadi acuan. Tahanan total software komputer adalah $286.75 \mathrm{kN}$ sedangkan tahanan metode matematis holtrop $256.59 \mathrm{KN}$. Dari keduanya terdapat selisih $10.52 \%$. 


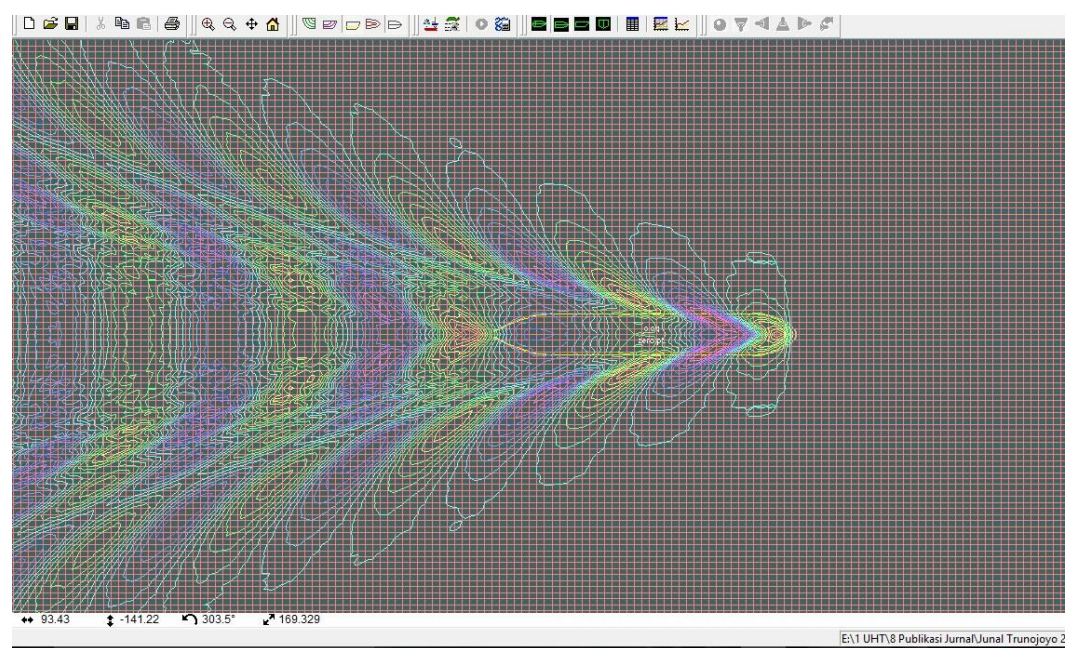

Gambar 5. Tampak atas alur gelombang ketika kapal bergerak

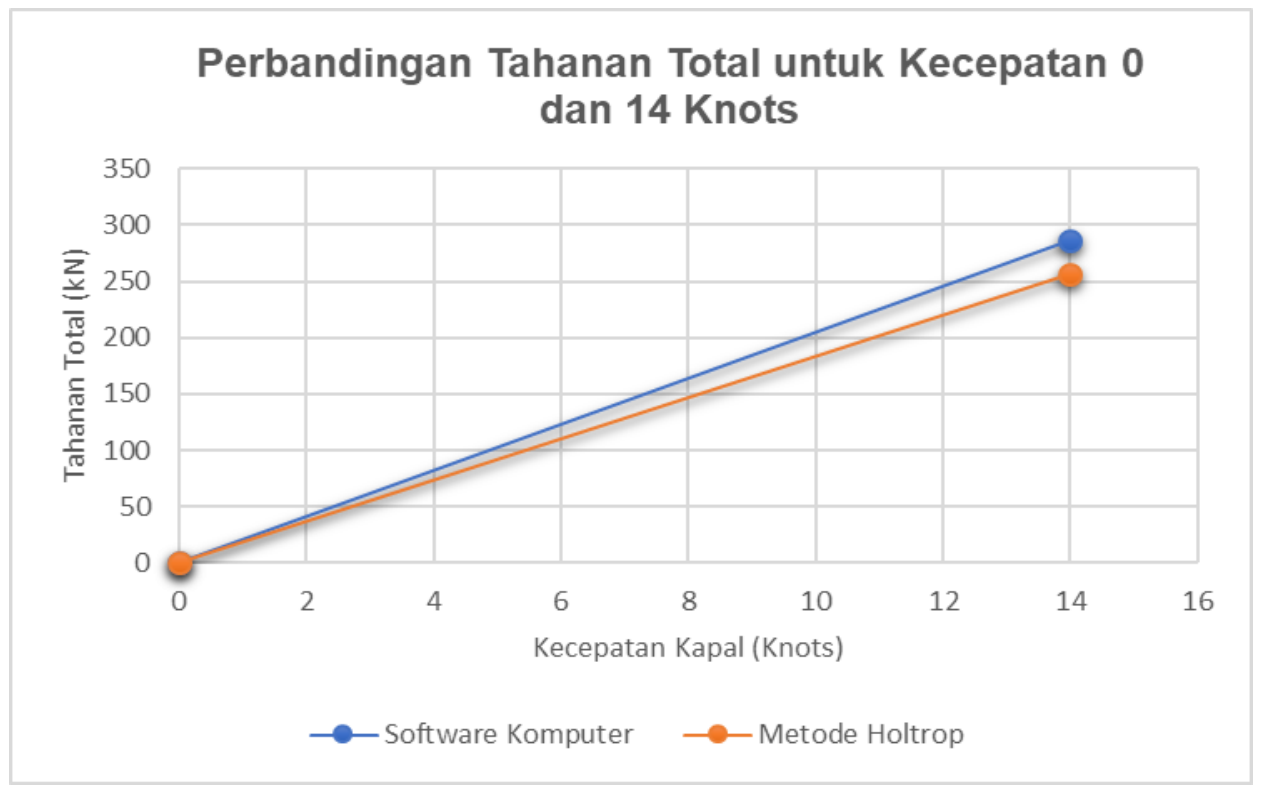

Gambar 6. Grafik Perbandingan Tahanan Total Bulk carrier

\section{Perbandingan dengan Tahanan Kapal} Tanker

Pada paper dengan judul Penggunaan Metode Komputerisasi dalam Penentuan Tahanan
Kapal Tanker (7) juga dilakukan penelitian penentuan tahanan kapal total namun untuk kapal tanker. Perbandingan perhitungan tahanan total dapat dilihat pada tabel 1 .

Tabel 1. Perbandingan Tahanan Total Buck Carrier dan Tanker

\begin{tabular}{|c|r|r|r|r|r|}
\hline Jenis Kapal & $\begin{array}{c}\text { Kecepatan } \\
\text { Kapal (Knot) }\end{array}$ & $\begin{array}{c}\text { Software } \\
\text { Komputer (KN) }\end{array}$ & $\begin{array}{c}\text { Metode } \\
\text { Holtrop (KN) }\end{array}$ & $\begin{array}{c}\text { Selisih } \\
(\mathrm{KN})\end{array}$ & Selisih (\%) \\
\hline \multirow{2}{*}{ Kapal Bulk Carrier } & 0 & 0 & 0 & & \\
\cline { 2 - 7 } & 14 & 286.75 & 256.59 & 30.16 & 10.517873 \\
\hline \multirow{2}{*}{ Kapal Tanker } & 0 & 0 & 0 & & \\
\cline { 2 - 7 } & 11.4 & 80.9 & 74.38 & 6.52 & 8.0593325 \\
\hline
\end{tabular}

Dengan membandingkan tahanan total kapal bulk carrier dan kapal tanker untuk kecepatan 0 dan kecepatan dinas masing-masing 14 dan
11.4 knots, dihasilkan selisih nilai tahanan total antara metode komputer dan metode holtrop adalah masing-masing $10.52 \%$ dan $8.06 \%$. 
Selisih nilai tahanan bulk carier lebih besar dari tanker karena ukuran kapal bulk carrier lebih besar dari tanker, sehingga volume yang tercelup fluida bulk carrier lebih besar dari tanker. Seperti juga pada gambar 7, kecepatan dinas bulk carrier lebih tinggi dari tanker. Ini menjadi alasan penting kenapa tahanan total bulk carrier lebih tinggi dibanding tanker

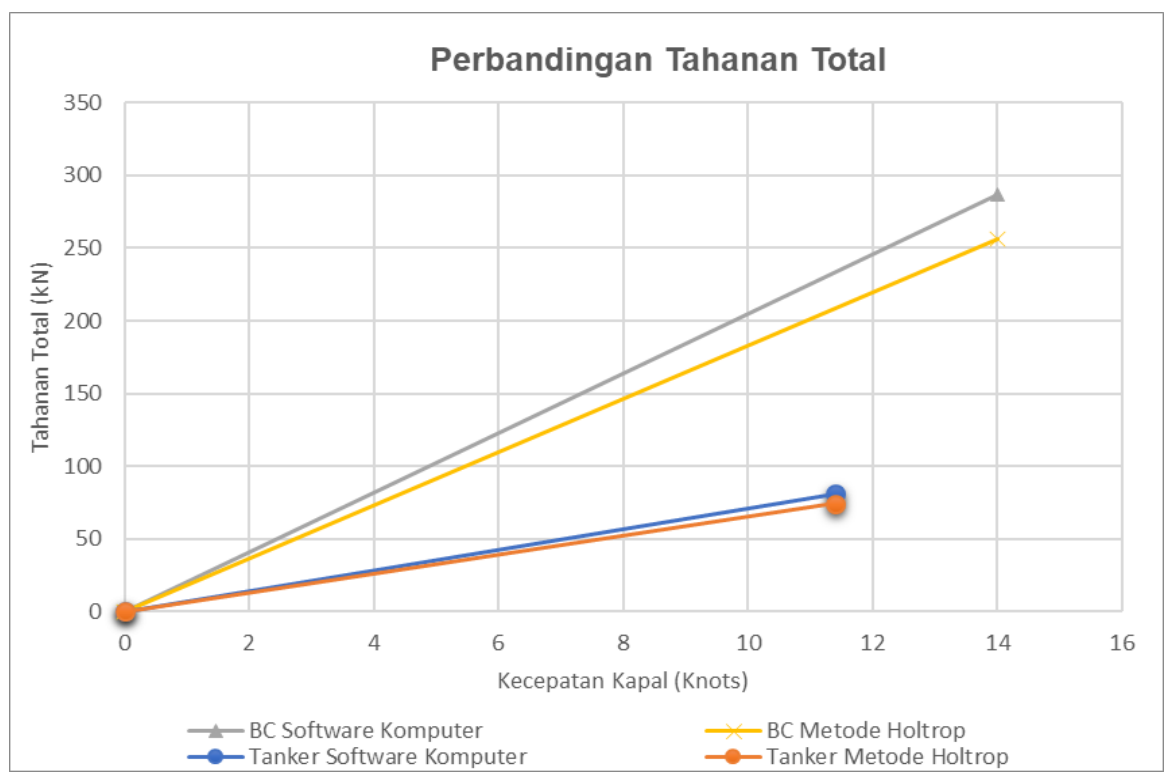

Gambar 7. Grafik Perbandingan Tahanan Total Buck Carrier dan Tanker

\section{KESIMPULAN DAN SARAN}

Dari Analisa dan pembahasan maka untuk kecepatan 0 sampai 2.5 knots dihasilkan tahanan dan daya bernilai 0 . Kemudian setelah kecepatan terus bertambah maka nilai tahanan dan daya mengikuti naik dengan pola persamaan garis linier kuadrat. Pada kecepatan maksimal kapal bulk carrier 14 knots menghasilkan nilai tahanan total kapal adalah 286. $75 \mathrm{kN}$ dan kebutuhan dayanya adalah $2950.31 \mathrm{~kW}$. Sedangkan dengan perhitugan matematis Holtrop dihasilkan tahanan total $256.59 \mathrm{kN}$, ini terdapat selisih $10.52 \%$ dengan hasil permodelan komputer.

\section{UCAPAN TERIMA KASIH}

Penulis mengucapkan terimakasih kepada Lembaga Penelitian dan Pengabdian Masyarakat Universitas Hang Tuah Surabaya atas hibah Penelitian Internal yang diberikan kepada penulis sehingga penulis dapat menyelesaikan karya tulis ini.

\section{DAFTAR PUSTAKA}

Muslihati, 2012. Analisis Biaya Operasi Kapal pada Berbagai Load Faktor Angkutan Perintis, Jurnal ILTEK, Volume 7, Nomer 14, Oktober. Makassar.
Parsons, Michael G. 1998. Parametric Ship Design Chapter 11. Univ of Michigan USA.

Watson, David G.M. 1998. Practical Ship Design Volume 1. Oxford. UK.

Rosmani, A., \& Algan, M. (2011). Prediksi Tahanan Kapal Cepat Dolpin Dengan Metode Eksperimen. Jurnal Teknik Universitas Hasanuddin: Makassar.

Susilo, J. S. J. S. J., \& Santoso, A. S. A. S. A. (2014). Simulasi Penggunaan Fin Undership Terhadap Tahanan dan Gaya Dorong Kapal dengan Metode Analisa CFD. Jurnal Teknik ITS, 3(2), G174-G179. ISSN: 2337-3539 (23019271). 2013. ITS Surabaya.

Lewis, E. V. (1988). Principles of Naval Architecture: Volume II-Resistance, Propulsion, and Vibration, Vol. 2, 2 edn, Soc. Naval Architects \& Marine Engineers.

Sugianto E, Puji H. 2017 "Metode Komputerisasi dalam Penentuan Tahanan Kapal Tanker". Seminar Nasional Teknik Mesin 2017, Universitas Jember. 